\title{
BRINCAR E EDUCAÇÃO: CONCEPÇÕES E POSSIBILIDADES
}

\author{
Alysson Massote Carvalho* \\ Maria Michelle Fernandes Alves \\ Priscila de Lara Domingues Gomes"
}

\begin{abstract}
RESUMO. O objetivo principal deste estudo foi analisar as relações existentes entre o contexto das instituições educativas e o comportamento de brincar de seus educandos. Foram participantes 40 crianças, de ambos os sexos, de idade entre 4 e 5 anos, e 10 educadores de cinco instituições educativas. Os procedimentos de coleta envolveram a filmagem das crianças em situação de recreação livre nas instituições e entrevistas com os educadores. Os principais resultados indicam que a estrutura da instituição educativa influencia o comportamento de brincar de seus educandos. Verificou-se também que existe uma dicotomia, em relação ao brincar, entre a visão e a prática dos profissionais. Esses resultados demonstram que é necessária uma articulação entre o projeto pedagógico, as práticas do currículo formal e o brincar, transformando e aprimorando a qualidade da educação nas instituições escolares.
\end{abstract}

Palavras-chave: Brincar, contexto educativo, desenvolvimento humano.

\section{PLAYING AND EDUCATION: CONCEPTIONS AND POSSIBILITIES}

\begin{abstract}
The goal of this study was to analyze the relations between educational institutions and the act of playing of their students. Subjects of the study were 40 children, of both genders, 4-5 years of age, and 10 educators of five preschool institutions. The procedures for data collection included the videotaping of the children during unstructured recreation in their own institution and interviews with the educators. The main results indicate that the educational institutes are influential over the play behavior of their students. It was also verified that there is incoherence between the understanding and the practice of the professionals, regarding play. These results indicate a necessity to integrate the pedagogical agenda, the practices of formal curriculum and play, transforming and improving the quality of education offered by educational institutions.
\end{abstract}

Key words: play, educational environment, human development.

No Brasil, tem-se observado uma preocupação crescente com a educação infantil. Isso pode ser identificado em vários níveis, dentre os quais se inclui o legislativo. De acordo com a Lei de Diretrizes e Bases da Educação Nacional -LDB(Brasil,1996), a educação infantil passa a ser parte educação básica, constituindo sua primeira etapa. Ela deve ser oferecida em creches e pré-escolas, com a finalidade de promover o desenvolvimento integral da criança até seis anos de idade. Esta mesma lei defende o pluralismo das idéias e das concepções pedagógicas, a fim de garantir excelência na educação.

Consoante a LDB, as Diretrizes Curriculares Nacionais para a Educação Infantil (Brasil, 1999) determinam que as instituições devem promover, além da educação formal, práticas de cuidado. Isso está em conformidade com a visão presente na LDB de integrar os aspectos físicos, psicológicos, intelectuais e sociais da criança, possibilitando seu desenvolvimento integral. Entre os fundamentos norteadores da educação infantil, essa resolução inclui a ludicidade e a criatividade.

Já nos Referenciais Curriculares Nacionais para a Educação Infantil - RCNEI (Brasil, 1998) há uma preocupação em sensibilizar os educadores para a importância do brincar tanto em situações formais quanto em informais. Neles, brincadeira é definida como a linguagem infantil que vincula o simbólico e a realidade imediata da criança.

No Estatuto da Criança e do Adolescente (Brasil, 1990) é explicitado o direito ao lazer, à diversão e a

\footnotetext{
* Doutor em Psicologia. Docente do Departamento de Psicologia da Universidade Federal de Minas Gerais-UFMG

\# Mestre em Psicologia pela Universidade Federal de Minas Gerais-UFMG.

^ Graduanda em Psicologia pela Universidade Federal de Minas Gerais-UFMG.
} 
serviços que respeitem a condição peculiar da criança e do adolescente como pessoas em desenvolvimento.

Verifica-se, com base nestes documentos, que de fato há uma preocupação legítima em promover melhores condições de desenvolvimento por meio da educação. Nesse contexto, a inserção do brincar pode constituir-se em um elemento importante para o ensino nas instituições educativas. Isso porque o brincar é um dos principais processos e uma das atividades mais presentes na infância, em que são construídas as capacidades e as potencialidades da criança (Moyles, 2002; Pereira, 2002).

Nessa perspectiva, Moyles (2002) apresenta uma visão de brincar, relacionada mais aos aspectos educativos. A autora entende esta atividade como um processo que ajuda a criança a confiar em si mesma e em suas capacidades para interagir socialmente com outras crianças e/ou com os adultos.

Já Ortega e Rosseti (2000) colocam que o uso do brincar permite a articulação entre os processos de ensino e da educação e exige uma postura ativa por parte do educando, que articula o ensino e a aprendizagem em um único movimento. Assim, a inserção do brincar livre, espontâneo, no currículo educacional e, conseqüientemente, nos projetos pedagógicos das instituições educativas, é um processo de transformação política e social em que crianças são vistas pelos educadores como cidadãs, isto é, cada uma como sujeito histórico e sociopolítico, que participa e transforma a realidade em que vive.

Avaliando a inserção do brincar no contexto educacional, Wajskop (1995) ressaltou que as instituições de educação infantil têm restringido as atividades das crianças aos exercícios repetidos de discriminação visual, motora e auditiva, através do uso de brinquedos, desenhos e músicas. Ao fazerem isso, ao mesmo tempo em que bloqueiam a organização independente das crianças para a brincadeira, essas práticas infantilizam os alunos, como se suas ações simbólicas servissem apenas para explorar e facilitar ao educador a transmissão de determinada visão de mundo, definida, a princípio, pela instituição infantil. Segundo Wajskop (1996), se as instituições fossem organizadas em torno do brincar infantil, elas poderiam cumprir suas funções pedagógicas, privilegiando a educação da criança em uma perspectiva criadora, voluntária e consciente.

Veale (2001), investigando o lugar do brincar nos programas contemporâneos de educação infantil, notou que nas práticas educativas não há tempo para desenvolver um aprendizado pelo brincar, já que o processo de escolarização e a preparação para a vida devem ser feitos com rapidez. Enquanto, na visão da criança, o brincar nunca desaparece, na documentação escrita presente nas instituições educativas a palavra brincar praticamente inexiste, sendo substituída freqüentemente pela palavra atividades.

Enfocando a questão do espaço para o lúdico, Dytz e Cristo (1995) destacaram a importância da ludoteca como local de brincadeiras nas instituições infantis. Ela é um espaço privilegiado de brincadeiras que estimula a imaginação, a fantasia e a compreensão do mundo por parte da criança. Fundamentando-se em Vygotsky, elas afirmaram que a atividade lúdica oferece uma válvula de escape para as fantasias da criança ante as pressões do mundo que a cercam. Posteriormente, Magalhães e Pontes (2002) assinalaram a criação e a manutenção das brinquedotecas como lugares, por excelência, do brincar. No entanto, os autores constataram que há uma significativa falta de fundamentação teórica, de organização espacial, e muita improvisação por parte dos gestores das brinquedotecas. A brinquedoteca passou a adequar-se aos objetivos e demandas da instituição, que não estão necessariamente condizentes com os objetivos e demandas das crianças.

Jorge e De Veasconcellos (2000) enfatizam uma ambivalência nas instituições educativas. De um lado, tem-se o universo da brincadeira e, de outro, o universo do estudo, do trabalho, da seriedade. Assim, ou se estuda ou se brinca, havendo pouca interação entre estes aspectos.

A partir das exposições desses autores, surgem alguns questionamentos: como, de fato, as rotinas de atividades influenciam as diversas funções que $\mathrm{o}$ brincar tem assumido nas instituições educativas? Até que ponto as concepções do brincar influenciam as atividades realizadas pelos educadores? Qual seria a influência que as diferentes funções do brincar têm no desenvolvimento infantil?

Essas questões serviram de referência e nortearam o presente estudo, que teve como objetivo descrever e analisar as relações existentes entre o contexto da instituição educativa e o comportamento de brincar de seus educandos.

O referencial teórico sobre desenvolvimento humano que norteou essa investigação é a abordagem ecológica do desenvolvimento proposta por Bronfenbrenner (1979, 1988, 1995), sinteticamente explicitada pela equação: $\mathrm{D}=f(\mathrm{PE})$, onde $\mathrm{o}$ desenvolvimento pode ser pensado como uma função integrada da pessoa com o seu meio (contexto). Nesse sentido, contexto das instituições educativas refere-se, basicamente, ao microssistema, ou seja, envolve um conjunto de atividades, de papéis e de relações 
interpessoais vivenciados por uma pessoa em um dado ambiente, sendo este com características físicas e materiais específicas. Logo, o microssistema refere-se àquele ambiente em que as pessoas podem interagir face a face, como uma casa, uma creche, uma préescola, dentre outros. Todavia, nele não são desprezadas as influências dos outros níveis propostos por Bronfenbrenner: o mesossistema, o exossistema e o macrossistema. Portanto, no caso do estudo apresentado, implica o ambiente físico, a rede de relações nele existente, a rotina de atividades e as concepções explícitas e implícitas sobre educação, desenvolvimento humano e principalmente sobre brincar, esposadas pelos educadores e coordenadores, e também pelas crianças. Consideramos existirem outros níveis relevantes também presentes no contexto das instituições educativas, os quais, porém, não serão objeto de análise neste estudo. Referem-se ao mesossistema (relações entre a família e a escola, por exemplo), ao exossistema (local de trabalho dos pais e sua influência sobre a criança) e ao macrossistema (concepções mais globais sobre educação e desenvolvimento presentes, por exemplo, nos documentos sobre políticas públicas para a educação, descritos anteriormente).

Analisando as concepções e as várias funções do brincar presentes na educação infantil, quer ocupando um lugar de recreação e de entretenimento, quer usado como recurso de ensino e de aprendizagem, é importante verificar qual o espaço do brincar nas instituições educativas, como as crianças brincam nestes contextos, e até em que medida a rotina de atividades e os projetos pedagógicos das instituições influenciam ou não o brincar das crianças.

\section{MÉTODO}

O modelo de investigação utilizado foi do tipo exploratório-descritivo, usando como recursos metodológicos a filmagem das crianças em situação de recreação livre, a entrevista semi-estruturada e a análise dos projetos pedagógicos. Neste artigo será priorizada a análise da filmagem das crianças e das entrevistas semi-estruturadas.

Os participantes foram 40 crianças, de ambos os sexos e da faixa etária de 4 e 5 anos, oriundas de 5 instituições educativas. Participaram também do estudo 10 educadores, sendo 5 professores e 5 coordenadores.

Os participantes foram filmados em situação de recreação livre, por meio de duas sessões com duração média de 25 minutos por instituição, com foco aleatório de 5 minutos por sujeito. Todas as filmagens foram realizadas nos ambientes externos das instituições, nos horários destinados a atividades livres em cada uma delas. $\mathrm{Na}$ instituição 1 havia cerca de 20 crianças por sessão; na instituição 2, 15 crianças; na instituição 3, 25 crianças; na instituição 4, 20 crianças e, na instituição 5, 24 crianças. Durante as filmagens, em todas as instituições, havia apenas uma turma de crianças em atividades livres.

As entrevistas foram realizadas na própria instituição dos profissionais.

Os episódios do brincar foram analisados a partir de algumas categorias definidas a priori, que são:

1. Idade: é a idade das crianças envolvidas no episódio de análise:

a) 4 anos: crianças de quatro anos;

b) 5 anos: crianças de cinco anos.

2. Composição Grupal: o número se sujeitos envolvidos no episódio de brincar:

a) uno: não há contato com nenhuma outra criança ou com adulto;

b) díade: quando o brincar ocorre entre duas crianças ou entre criança e adulto;

c) tríade: quando ocorre entre três crianças ou entre crianças e adultos, no total de três participantes;

d) políade: quando ocorre entre quatro ou mais crianças ou entre crianças e adultos, com a participação de quatro ou mais sujeitos.

3. Gênero: o sexo dos sujeitos envolvidos:

a) masculino: quando a brincadeira ocorre somente entre sujeitos do sexo masculino;

b) feminino: quando a brincadeira ocorre somente entre sujeitos do sexo feminino;

c) misto: quando a brincadeira ocorre entre sujeitos do sexo masculino e do feminino.

4 - Relação estabelecida: a maneira pela qual os sujeitos envolvidos no episódio de brincar estabelecem uma relação com outro sujeito.

a) criança-criança: quando a brincadeira envolve apenas crianças;

b) criança-adulto: quando um ou mais adultos participam da brincadeira com uma criança;

c) criança-adulto-criança: quando duas ou mais crianças brincam com um ou mais adultos.

\section{5 - Tipo de brincadeira}

- Faz-de-conta: é toda brincadeira que transcende o limite da realidade, ocorrendo dentro do 
contexto da fantasia. É aquela brincadeira em que há a substituição/tranasformação de um objeto por outro ou de uma pessoa por uma personagem, com a qual a criança utiliza sua criatividade e sua imaginação.

a) Brincar de cuidar: é quando as crianças brincam com a finalidade de representar um cuidado efetivo, ou seja, alimentar através de gesto representativo, como também vestir, pentear, ajudar, etc. Pode ser também aquela brincadeira em que as crianças assumem papéis típicos de cuidadores ou alvos de cuidado, como, por exemplo, mamãe/filhinha e médico/paciente (Carvalho, 1999);

b) Brincar de fantasia: é quando as crianças brincam com a finalidade de representar uma personagem, tanto pessoas como animais, como também situações fictícias;

c) Brincar de realidade: é quando as crianças brincam imitando papéis sociais estabelecidos, por exemplo, professor, guarda, pai, mãe, filho, etc, e quando também imitam situações da realidade, como mover um helicóptero de brinquedo, sem envolver os aspectos descritos nas subcategorias "brincar de cuidar" e "brincar de fantasia".

- Jogos: é o conjunto de brincadeiras que envolvem regras preestabelecidas.

a) Movimento físico: são aquelas brincadeiras que envolvem movimentos físicos amplos, como também coordenação motora, como, por exemplo, pular amarelinha, pular corda, jogar bola, girar bambolê, etc.

6. Estilo de interação: é o modo como os sujeitos interagem no episódio de brincar:

a) solitário: quando as crianças brincam longe umas das outras, concentradas no que fazem, sem dar atenção ao que as outras crianças estão fazendo;

b) independente: quando duas ou mais crianças estão brincando próximas umas das outras, não havendo tentativa de influenciar a brincadeira do outro;

c) assimétrico: quando duas ou mais crianças estão brincando separadamente havendo uma tentativa de estabelecer algum contato entre si, envolvendo ou não um terceiro, adulto, e existindo uma tentativa de influência recíproca, porém sem complementaridade das ações;

d) complementar: quando duas ou mais crianças estão brincando juntas, havendo influência recíproca e envolvendo ou não um terceiro; pode também ser um adulto; a ação de uma é complementada pela ação de outra, por exemplo: dois meninos brincando de superheróis, sendo um Batman e o outro Robin.

7 Caráter social: abrange uma regulação mútua entre os organismos, ou seja, estes possuem a propriedade de regular e de serem regulados pelo seu co-específico.

a) agonístico: tipo de relação em que duas ou mais crianças, independentemente do contexto do brincar, desempenham ações de agressividade, lutas, disputas, etc.;

b) pró-social: tipo de relação em que duas ou mais crianças, independentemente do contexto do brincar, desempenham ações que envolvem amizade, cumplicidade, confiança, afinidade, etc.

8. Instituições: o item refere-se às instituições educativas participantes da pesquisa:
a) instituição 1
b) instituição 2
c) instituição 3
d) instituição 4
e) instituição 5

Para análise das entrevistas utilizou-se como referencial a Análise de Conteúdo, que é um conjunto de técnicas de análise das comunicações, buscando obter indicadores que permitam tirar conclusões referentes aos conhecimentos relativos às condições de produção/recepção das mensagens advindas do ato de se comunicar (Bardin, 1988).

A seguir, segue uma breve descrição das instituições onde ocorreram as observações.

A instituição 1 é uma instituição sem fins lucrativos, que busca capacitar a criança para a vida, oferecendo oportunidades para que a criança desenvolva ao máximo seus potenciais. Atualmente, atende a 318 crianças, na faixa etária entre 3 meses e 7 anos. Sua área externa é composta por um pátio coberto, onde se encontram vários brinquedos, e área livre, incluindo um campo de futebol e um pátio a céu aberto com jardins. Sua área interna é composta por salas de aula específicas para cada faixa etária, e o bloco de atividades comuns (biblioteca, sala de multimeios, brinquedoteca, refeitórios, cozinha, sala dos funcionários e os almoxarifados). Há horário para atividades livres todos os dias da semana (10:30- 
11:30). Há uma brinquedoteca, que cada turma de crianças pode utilizar.

A instituição 2 é uma instituição comunitária subsidiada pela prefeitura de um município e por convênios. Pauta-se pelo respeito e pelos direitos das crianças em suas diferenças individuais, sociais, econômicas, culturais, étnicas e religiosas. Atende a 42 crianças de 2 a 5 anos. Sua área externa inclui um espaço coberto para atividades coletivas, parque infantil (playground), horta comunitária, área verde e teatrinho de arena. Sua área interna inclui salas de aula, sala de atividades, biblioteca, cozinha, almoxarifado, brinquedoteca e lavanderia. Os horários diários para atividades livres nessa instituição são das nove às dez horas e das catorze e trinta às dezesseis horas. O professor também poderá utilizar esses horários para atividades programadas, dependendo do seu planejamento semanal. Nessa instituição, as turmas têm acesso diário à brinquedoteca, cada uma em um horário específico.

A instituição 3 é uma instituição municipal, cujas instalações foram construídas pela prefeitura de um município diferente daquele da instituição 2 , para promover o desenvolvimento físico das crianças, através da complementação alimentar, bem como ampliar as experiências e os conhecimentos infantis. Atualmente tem 408 crianças arroladas, na faixa etária de 0 a 6 anos. Sua área externa dispõe de uma casa de bonecas, pátio coberto e não coberto, parquinho, poço de areia e área gramada. Sua área interna, além das salas de aula, possui biblioteca, sala de multimeios, cozinha, anfiteatro, refeitório e almoxarifado. Nessa instituição as crianças têm, diariamente, os horários das dez às onze e das catorze horas e quinze minutos às quinze horas para atividades livres ou pedagógicas, em função do projeto do professor, semelhantemente à instituição 2. Quanto à brinquedoteca, as crianças de 0 a 4 anos têm acesso diário, em horários específicos; já as crianças de 5 e 6 anos têm acesso apenas uma vez por semana.

A instituição 4 é uma instituição particular, com 155 alunos de 2 a 6 anos, atendendo a uma população de classe média alta. Busca desenvolver na criança uma imagem positiva de si, ampliando a auto-estima, a autonomia e os conhecimentos. Sua área externa é composta por dois pátios (um coberto e um não coberto), duas quadras (uma de cimento e outra de grama) e brinquedos diversos. Sua área interna se constitui de seis salas de aula, sala de inglês e sala de música. O horário diário para atividades livres na instituição era das dezesseis e trinta às dezessete e trinta. Essa instituição não possui brinquedoteca.
A instituição 5 pertence à rede municipal de ensino do mesmo município da instituição 2 . Atende a um total de 212 crianças, na faixa etária de 3 a 5 anos. Preocupa-se em construir o conhecimento do aluno a partir de seus interesses e necessidades. Em sua área externa existe um pátio. Sua área interna possui salas de aula, biblioteca, refeitório e cantinho da fantasia (sala que contém fantoches e fantasias utilizadas pelas crianças). Nessa instituição as crianças possuem o horário das catorze às quinze horas, diariamente, para atividades livres. Semelhantemente à instituição 4, não possui brinquedoteca.

Naquelas instituições que possuem brinquedoteca o padrão de utilização é muito semelhante: as atividades realizadas são mais livres, com as crianças tendo a oportunidade de escolher os brinquedos e as brincadeiras. O professor, por sua vez, tem o papel de auxiliar as crianças quando solicitado, não interferindo muito em suas atividades. O tempo médio de utilização das brinquedotecas era cerca de 40 minutos, diários ou semanais, conforme o padrão de cada instituição descrito anteriormente.

Em todas as instituições havia superposição de 30 minutos do horário de recreio com aquele para atividades livres, exceto o destinado às atividades livres no período da tarde na instituição 3 .

\section{RESULTADOS E DISCUSSÃO}

\section{Observações}

Foram analisados, no total, 231 episódios de brincar. Eles foram classificados a partir das categorias descritas no item Metodologia. Foi utilizada a técnica estatística CHAID (Detector Automático de Interação Baseado em Quiquadrado). Esta técnica segmenta uma amostra em vários subgrupos, com base no melhor preditor de uma variável dependente, e depois os organiza hierarquicamente em níveis de profundidade. A segmentação é feita por ordem decrescente dos níveis de significância até que não haja mais nenhum preditor estatisticamente significativo. Para executar tal divisão, essa técnica constrói diagramas de árvores que representam graficamente os dados avaliados, apresentando-os de maneira gradativa, tendo como parâmetro as segmentações feitas pelo CHAID.

$\mathrm{Na}$ análise CHAID para a variável "Tipo de brincadeira", foi observado o predomínio do movimento físico, seguido pelo brincar de realidade. 


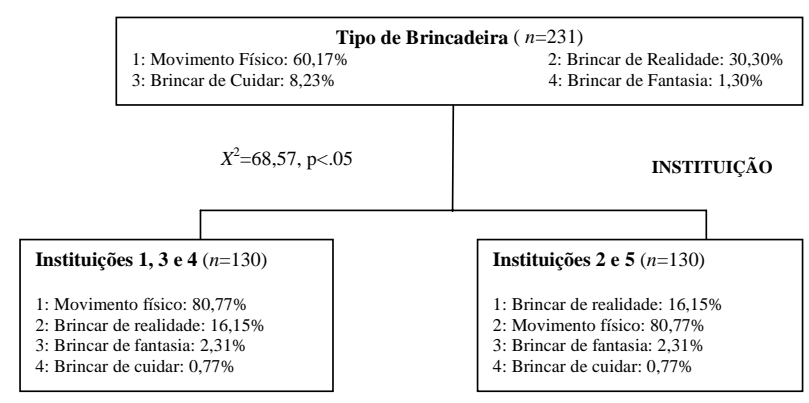

Figura 1. Diagrama CHAID para a variável tipo de brincadeira

A única segmentação feita para esta variável foi para o preditor "Instituição", com a formação de dois subgrupos. No primeiro deles, constituído pelas instituições 1,3 e 4 , houve um predomínio do movimento físico, com $80,77 \%$ de ocorrência, seguido pelo brincar de realidade, com 16,15\%. Nessas instituições, observou-se que o horário de recreação livre destina-se para brincadeiras que exploram o espaço físico. No outro agrupamento, formado pelas instituições 2 e 5, houve um equilíbrio de frequiências entre o brincar de realidade e o movimento físico. É interessante observar que o brincar de cuidar aparece significativamente mais neste subgrupo, com 17,82\%, em detrimento do outro, com apenas $0,77 \%$ de ocorrência. Nestas instituições, no horário de recreação livre, as crianças, além do espaço físico, podem utilizar outros brinquedos (da brinquedoteca ou da caixa de brinquedos).

$\mathrm{Na}$ variável "Relação estabelecida", constatou-se o predomínio da relação criança-criança, com 51,08\% de ocorrência, conforme mostrado na figura 02 . Houve, também, uma grande porcentagem de crianças brincando sozinhas, com 45,02\%. A primeira segmentação foi para o preditor "Caráter social", com a formação de dois subgrupos. Observaram-se, predominantemente dentro da relação criança-criança, comportamentos tanto agonísticos como pró-sociais, com $92,91 \%$ de ocorrência. A participação do adulto ficou restrita a um total de $7,08 \%$.

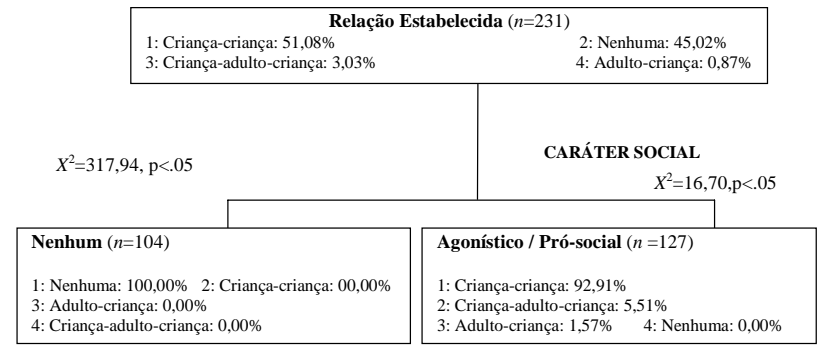

Figura 2. Diagrama CHAID para a variável relação estabelecida, relativa à $1^{\mathrm{a}}$ segmentação
$\mathrm{Na}$ última segmentação, o preditor "Instituição" foi referência para a formação de dois novos agrupamentos, apresentados na figura 03 . No primeiro agrupamento, formado pelas instituições 1 e 4, observou-se uma frequiência significativa para a relação criança-criança, seguida pela criançaadulto-criança. No outro subgrupo, constituído pelas instituições 2 , 3 e 5 , foi verificado um total de $100,00 \%$ na relação criança-criança. Notou-se que, em todas as instituições, no horário de recreação livre, o professor assume o papel de observador, interferindo nas brincadeiras apenas quando solicitado.

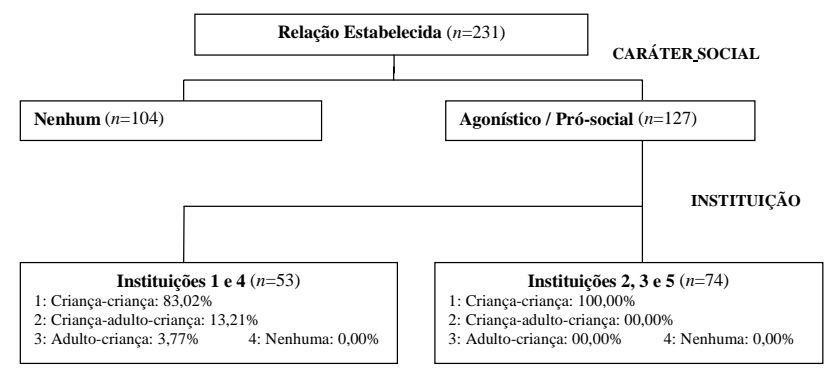

Figura 3. Diagrama CHAID para a variável relação estabelecida, relativa à $2^{a}$ segmentação

Assim, os profissionais parecem conceber a recreação livre como o horário em que as crianças brincam livremente, de forma espontânea e que, conseqüentemente, não exigiria a sua participação de maneira efetiva, já que não envolve, a princípio, a aprendizagem de conteúdos.

$\mathrm{Na}$ análise para a variável "Caráter social" , como mostrado na figura 04 , observou-se que as crianças brincam mais pró-socialmente. Verificou-se também que, devido à alta porcentagem de crianças brincando sozinhas, houve uma elevada frequiência de nenhum caráter social.

$\mathrm{Na}$ única segmentação feita para esta variável, com o preditor "Composição grupal", verificou-se que, nas composições díade, tríade e políade, as crianças brincaram mais pró-socialmente do que agonisticamente.

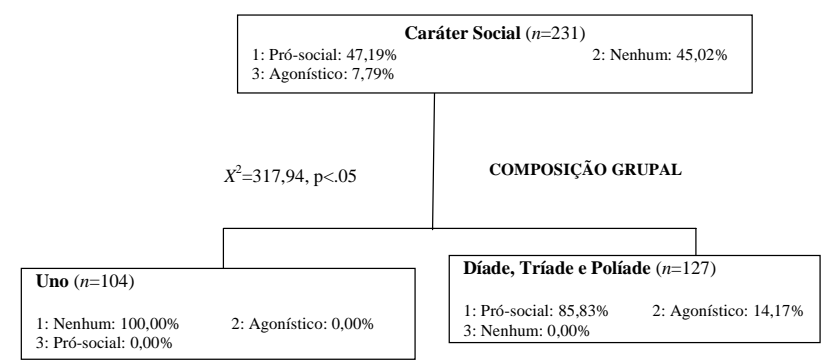

Figura 4. Diagrama CHAID para a variável caráter social 
Na variável "Composição crupal" verificou-se que as crianças brincaram mais sozinhas, como apresentado na figura 05. A segmentação feita para esta variável foi para o preditor "Caráter social". Notou-se que, seja em brincadeiras agonísticas seja em pró-sociais, a composição predominante foi díade, seguida por políade.

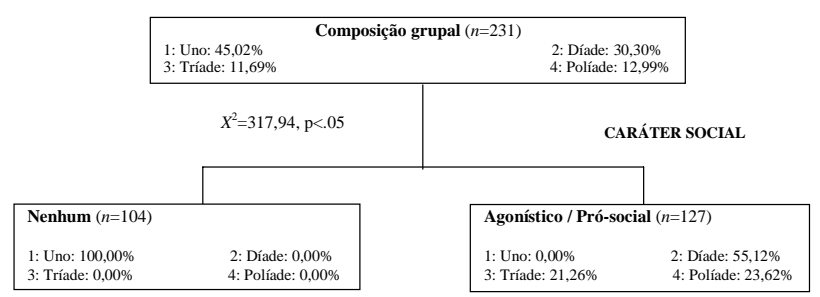

Figura 5. Diagrama CHAID para a variável composição grupal

Na análise CHAID para a variável "Estilo de interação", observou-se uma frequiência significativa no estilo solitário, conforme mostrado na figura 06. $\mathrm{Na}$ única segmentação feita para esta variável, o preditor "Caráter social" foi referência para a formação de dois subgrupos. Nas brincadeiras agonísticas e pró-sociais, o estilo de interação predominante foi o complementar.

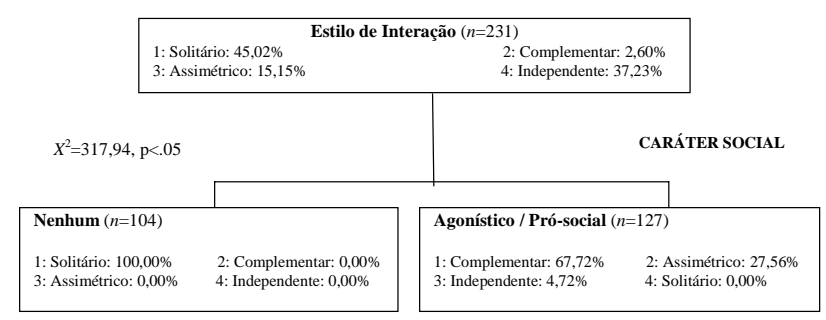

Figura 6. Diagrama CHAID para a variável estilo de interação

Assim, a análise CHAID apontou uma grande porcentagem de crianças brincando sozinhas, sem estabelecer relações. Quando as estabeleceram, a relação predominante foi criança-criança, com estilo complementar. Também ocorreu o predomínio de brincadeiras que envolveram movimentos físicos e o brincar de realidade, com caráter pró-social.

A rotina de atividades das instituições e as concepções dos educadores sobre o brincar parecem influenciar as brincadeiras das crianças nas instituições, que são direcionadas a uma maior exploração física dos ambientes - como aquelas que estimulam a coordenação motora - e pouca participação dos adultos. O contexto educativo é um fator significativo que influencia a atividade de brincar das crianças, tal como foi constatado nos estudos de Carvalho (1999) e Wajskop (1995).

\section{Entrevistas}

Para análise dos dados obtidos nas entrevistas dos professores e coordenadores, utilizou-se a técnica de Análise de Conteúdo, explicitada no item Metodologia. No Roteiro de Análise foram abordados os seguintes temas: rotina da instituição educativa, concepções do projeto pedagógico, construção do projeto pedagógico, concepções da atividade de brincar, relação do brincar com o desenvolvimento infantil, espaços para o brincar na instituição educativa, utilização do brincar (material, tempo, brincadeiras mais comuns, planejamentos) na rotina institucional, papel do brincar na instituição educativa.

As rotinas nas instituições educativas, segundo seus profissionais, mostraram-se bastante diferenciadas umas das outras, já que são influenciadas pelo objetivo da instituição e também pela faixa etária atendida. No entanto, foi possível encontrar algumas atividades e práticas em comum presentes nas instituições, como a roda inicial com as crianças, o lanche, o cuidado com a higiene dos educandos e a preocupação com as atividades realizadas pelos professores com as crianças (planejamento de atividades).

Notou-se que apenas os coordenadores das instituições 2 e 4 destacaram a presença de brincadeiras livres na rotina institucional. Verificou-se que, em nenhum momento, os professores mencionaram a palavra brincar como parte integrante da rotina institucional ou como elemento que subsidiasse as atividades realizadas com as crianças.

Os professores, como os coordenadores, seguindo as leis que regem a educação infantil, também adotaram, na rotina institucional, as dimensões de cuidar e de educar como modo de garantir o pleno desenvolvimento infantil. $O$ cuidar aparece na valorização e na ajuda às crianças, para desenvolverem capacidades que dependem tanto dos cuidados relacionais - que envolvem a dimensão afetiva e os cuidados com os aspectos biológicos do corpo - quanto da qualidade de alimentação e dos cuidados de saúde. Já a dimensão de educar está relacionada a propiciar às crianças situações de cuidado e de aprendizagem, buscando contribuir para o seu desenvolvimento integral.

Quanto à concepção do projeto pedagógico, os profissionais o mencionaram como um conjunto de ações que objetiva organizar e estruturar a instituição educativa para poder atingir seus objetivos. Além disso, enfatizaram que o projeto nunca está acabado, já que implica, necessariamente, um refazer constante, dando a idéia de um processo. O projeto nortearia as atividades realizadas pelos profissionais com as 
crianças, subsidiaria a rotina de atividades nas instituições, seria um instrumento para melhor compreender a criança, o seu desempenho e as etapas de seu desenvolvimento.

Verificou-se, pelas entrevistas, que a construção dos projetos pedagógicos, em todas as instituições educativas, envolveu principalmente a participação dos profissionais das instituições, incluindo professores, coordenadores e diretores, com a idéia de ser uma construção coletiva. No entanto, o envolvimento da comunidade e dos pais só foi mencionado nas instituições 2 e 5, e a participação dos alunos apareceu somente na instituição 3 .

As concepções da atividade de brincar puderam ser categorizadas em quatro aspectos: recreação, criatividade, natureza infantil e desenvolvimento e socialização. Como recreação, os professores perceberam o brincar como uma atividade prazerosa, divertida, em que a criança tem a possibilidade de expressar seus sentimentos e seus desejos; porém este aspecto não apareceu nas concepções dos coordenadores. $\mathrm{O}$ brincar proporciona à criança mexer com o seu corpo e com a sua mente, podendo mostrar o que gostaria de ser e de representar, e é uma expressão de sua criatividade. Pelo brincar a criança se desenvolve, constrói conceitos e valores e resolve problemas. É uma atividade natural da criança, sendo a primeira fase de aprendizagem. O brincar também foi classificado como elemento de socialização, pois através dele a criança aprende as regras e os limites, o que a ensina a viver em sociedade.

As concepções dos professores e coordenadores estão em conformidade com os estudos relacionados ao brincar, como os apresentados por Brown (1998) e Pires (1989), os quais enfatizaram os ganhos que o brincar traz para o desenvolvimento infantil.

As relações estabelecidas pelos entrevistados entre o brincar e o desenvolvimento infantil puderam ser percebidas de várias maneiras. Para os profissionais, o brincar é inerente à infância, estando sempre presente no desenvolvimento infantil, além de construir valores e organizar conceitos frente à realidade da criança. O lúdico é um mecanismo de socialização do educando, inserindo-o no mundo, ensinando-o a respeitar o direito de outras crianças e conhecer os limites. A criança também aprende a ser autônoma, já que, pelo brincar, a criatividade e o raciocínio são estimulados. Isso possibilita alfabetizála, já que, pela brincadeira, ela aprende os números, as cores, as letras. Nas instituições 2 e 5 isso teve maior destaque por parte dos coordenadores.

As relações estabelecidas pelos coordenadores são congruentes com os estudos relacionados ao brincar, como o apresentado por Pires (1989), que ressalta a importância desta atividade para o desenvolvimento, pois há a aquisição de habilidades, da socialização e do conhecimento de si e da realidade, por meio de interação e de brincadeiras. No entanto, observou-se que na entrevista com os professores, de maneira geral, não houve referência ao brincar como recurso didático usado para alfabetização ou ensinar conteúdos, como apresentado nas entrevistas com os coordenadores.

Os espaços relacionados por todos os profissionais para o brincar foram os espaços externos, auditório, multimeios, refeitório, sala de televisão, vídeo e horário do recreio. Constatou-se que os professores das instituições 1, 4 e 5 destacaram a sala de aula como espaço importante para o brincar das crianças, assim como todos os coordenadores. $\mathrm{O}$ coordenador da instituição 1 foi o único a não relatar a sala de aula como espaço para o brincar. Observou-se que, diferentemente dos seus coordenadores, os professores das instituições 1 e 2 relacionaram a existência da brinquedoteca. Sua utilização é mais livre, já que as crianças têm a possibilidade de criar as suas próprias brincadeiras. Apesar de o professor da instituição 3 não falar da brinquedoteca, o coordenador desta instituição relatou a existência dela.

Para os professores que relataram a sala de aula como espaço para o brincar, as brincadeiras que ocorrem nesse espaço desenvolvem nas crianças, principalmente, a coordenação motora fina, a concentração e a atenção. Notou-se que os profissionais privilegiam os espaços externos com as brincadeiras que exploram o espaço físico da instituição e a coordenação motora grossa.

Quanto à participação dos professores nas brincadeiras, os entrevistados das instituições 2,3 e 4 disseram que participam ativamente das brincadeiras, já que têm a função de direcionar, organizar e ensinálas; já os entrevistados das instituições 1 e 5 esclareceram que somente participam das brincadeiras quando elas são direcionadas, possuindo objetivos específicos; caso contrário, apenas se envolvem nas brincadeiras dos educandos quando solicitados.

Constatou-se que os professores entrevistados parecem privilegiar o brincar atrelado a um objetivo, com o intuito de passar conteúdos específicos para a aprendizagem das crianças. Assim, tal como foi observado nas entrevistas dos coordenadores e nos estudos de Kishimoto (1997); Veale (2001); Wajskop (1996). o uso do brincar remete a um recurso metodológico para fim de aprendizagens orientadas. $\mathrm{O}$ brincar livre, sem um direcionamento, fica restrito aos horários do recreio ou àqueles em que as crianças 
ficam juntas com outras de faixas etárias diferentes, como, por exemplo, na chegada e na roda inicial dos educandos.

O papel do brincar nas instituições educativas foi destacado, basicamente, pelos coordenadores. Eles afirmaram, exceto o profissional da instituição 3, que é função das instituições de educação infantil resgatar o brincar, criando oportunidades e espaços, seja para o brincar pedagógico seja para o brincar livre. Além disso, é fundamental descobrir e trazer a importância e o significado do brincar para os pais, possibilitando, inclusive, uma integração entre família e escola. Os profissionais, então, entenderam o brincar como prática importante para o desenvolvimento infantil. A função que assume o brincar parece mais atrelada a um planejamento de cunho pedagógico, e por isso mesmo os entrevistados destacaram a necessidade de se resgatar o brincar, inclusive, no âmbito do divertimento, de recreação.

Os professores das instituições 1, 3, 4 e 5 enfatizaram a importância desta atividade para o desenvolvimento infantil e a valorização do brincar na instituição como prática presente na rotina institucional. O entrevistado da instituição 2 destacou que, se o brincar é organizado, planejado, tem uma maior aceitação por parte da instituição, sobretudo por parte do diretor e do coordenador. Verificou-se que, para os professores, é importante esta atividade estar presente nas instituições, subsidiando o trabalho deles com as crianças.

Analisando as entrevistas dos coordenadores e professores separadamente, notaram-se alguns aspectos contraditórios, como, por exemplo, a relação do brincar com o desenvolvimento e com a presença da brinquedoteca nas instituições. Os profissionais, ao entenderem a presença do brincar nas instituições principalmente associada a um planejamento em atividades direcionadas, com o intuito de aprendizagem, parecem dar pouco incentivo às situações de brincadeira que ocorrem livremente, já que não envolvem, a princípio, os objetivos didáticos estabelecidos. É importante ressaltar, ainda, uma incongruência teórica e prática presente no relato dos professores. Ao mesmo tempo que não citaram o brincar como elemento constituinte da rotina das crianças e não relacionaram esta atividade como um elemento mediador da aprendizagem na prática, tais profissionais entenderam o brincar como parte integrante da rotina das crianças e como meio, por excelência, usado em atividades didáticas, para fim de ensino e de aprendizagem.

Sintetizando, verificou-se que o contexto educativo influencia o brincar das crianças. Observou- se que as brincadeiras mais significativas foram movimento físico e o brincar de realidade. Este dado está em conformidade com a filosofia de trabalho das instituições, já que o horário de recreação livre é associado a um momento de a criança explorar o ambiente físico da instituição de uma maneira criativa e livre. Verificou-se também uma ambivalência referente à inserção do brincar na rotina das instituições. De um lado, o brincar apareceu na rotina institucional de maneira totalmente livre, sem objetivos e planejamento, associado a uma idéia de diversão, de lazer, de entretenimento; por outro lado, assumia a função de um recurso pedagógico utilizado pelo educador, com objetivos definidos e um planejamento.

As atividades pedagógicas trabalhadas pelos professores, que usam o brincar como suporte, são utilizadas como treino de coordenação motora fina, aprendizagem do alfabeto, numerais ou outras habilidades. Conseqüentemente, o brincar como expressão máxima da fantasia, das representações, da imaginação, da criatividade, da autonomia, da socialização, vai perdendo cada vez mais espaços nas instituições. Tal fato poderia estar relacionado ao modo como o brincar está inserido nas rotinas das instituições e nos projetos pedagógicos, em termos de concepções e de atividades.

Estes dados corroboram o que alguns autores já têm apontado: que o brincar, muitas vezes, está assumindo uma posição ambígua na instituição educativa. Ora é utilizado como recurso de ensinoaprendizagem pelos educadores, ora é colocado como forma de expressão livre, espontânea da criança (De Veasconcellos; Jorge, 2000; Kishimoto, 1997; Wajskop, 1996).

Assim, os resultados da investigação apontaram questões importantes não só para os pesquisadores da área como também para os educadores que trabalham nas instituições educativas. É, de fato, importante que os profissionais repensem o lugar que o brincar está ocupando dentro das instituições educativas, criando na rotina de atividades mais espaços para brincadeiras. Devem envidar esforços para estabelecer uma articulação entre o brincar, o projeto pedagógico e a rotina de atividades, subsidiando a qualidade do atendimento das instituições educativas.

Concluindo, a pesquisa corroborou os estudos recentes sobre o brincar, destacando a importância desta atividade para o desenvolvimento infantil e para as instituições educativas. Além disso, enfatizou a utilização do brincar nesses contextos para que ele possa ser, de fato, um facilitador para o desenvolvimento humano. 


\section{REFERÊNCIAS}

Bardin, L. (1988). Análise de conteúdo. Lisboa: Edições 70.

Brasil (1990). Estatuto da Criança e do Adolescente. Diário Oficial da União, Lei no 8.069, de 13.07.1990, Brasília.

Brasil.(1996). Ministério da Educação e do Desporto. Lei Federal ${ }^{\circ}$ 9394, de 20 de dezembro de 1996. Diretrizes e Bases para a Educação Nacional. Diário Oficial da União. Brasília.

Brasil.(1998). Ministério da Educação e do Desporto. Secretaria de Educação Fundamental Referencial Curricular Nacional para a Educação Infantil. Brasília: MEC/SEF.

Brasil.(1999). Ministério da Educação e do Desporto. Resolução CEB01, de 04 de abril de 1999. Diretrizes Curriculares Nacionais para a Educação Infantil. Diário Oficial da União. Brasília.

Bronfenbrenner, U. (1979). The ecology of human development: experiments by nature and design. Massachusetts: Harvard University Press.

Bronfenbrenner, U. (1988). Interacting systems in human development. Research paradigms: Present and future. Em N. Bolger, C. Avshalom, G. Downey \& M. Moorehouse (Org.), Persons in context. Developmental processes, (Vol. 2, pp. 2549). New York: Cambridge University Press.

Bronfenbrenner, U. (1995). Developmental Ecology through space and time: a future perspective. Em P. Moen, G. Elder Jr. \& K. Lüscher (Org.), Examining lives in context- Perspectives on the logy of human development, (Vol. 19, pp. 619-647). Washington: American Psychological Association.

Brown, S. (1998). Play as an organizing principle: clinical evidence and personal observations. Em M. Bekoff \& J. A. Byers (Org.), Animal play (pp. 170-210) Cambridge: Cambridge University Press.

Carvalho, A. M. (1999). O mundo social da criança: natureza e cultura em ação. São Paulo: Casa do Psicólogo.

Dytz, J. \& Cristo, R. (1995). A ludoteca como espaço para uma nova abordagem de educação em saúde. Revista Brasileira de Enfermagem, 48(2), 134-139.
Jorge, A. S. \& de Veasconcellos, V. M. R. (2000). Atividades lúdicas e a formação do educador infantil. Revista do Departamento de Psicologia, 12(2-3) 55-67.

Kishimoto, T. M. (1997). Brinquedo e Brincadeira na educação infantil japonesa: proposta curricular dos anos 90. Revista Educação e Sociedade, 18(60), 64-88.

Magalhães, C. \& Pontes, F. (2002). Criação e manutenção de brinquedotecas: reflexões acerca do desenvolvimento de parcerias. Psicologia: Reflexão e Crítica, 15(1), 235-242.

Moyles, J. R. (2002). Só brincar? O papel do brincar da educação infantil. Porto Alegre: Artmed.

Ortega, A. C. \& Rossetti, C. B.(2000). A concepção de educadores sobre o lugar do jogo na escola. Revista do Departamento de Psicologia, 12(2-3), 45-53.

Pereira, E.T. (2002) Brinquedos e infância. Revista Criança: Do Professor de Educação Infantil, 37, 7-9.

Pires, G. N. da L. (1989). A Brinquedoteca e o jogo infantil como representação do mundo adulto e a aprendizagem dos modelos sociais. Educação em debate, 12(17-18), 67-77.

Veale, A. (2001). Revisiting the landscape of play. Early Child Development and Care, 171(1), 65-74.

Wajskop. G. (1995). Brincar na pré-escola. São Paulo: Cortez.

Wajskop, G. (1996). Concepções de brincar entre profissionais de educação infantil: implicações para a prática institucional. Tese de Doutorado Não-Publicada, Programa de PósGraduação em Educação, Pontifícia Universidade Católica de São Paulo, SP.

Endereço para correspondência: Alysson Massote Carvalho, Rua Engenheiro Vicente Assunção, 77B, Itapoá, CEP 31710-090, Belo Horizonte-MG. E-mail: alysson@ufmg.br 